\title{
The Influence of New Media on the Life of Contemporary Youth
}

\author{
Fei Wang ${ }^{1, *}$ \\ ${ }^{1}$ Commercial College, Tianjin University of Finance and Economics, Tianjin 300221, China \\ *Corresponding author. Email: 2460424870@qq.com
}

\begin{abstract}
Based on the impact of BiliBili website crash on multiple websites and the great attention it has received, it is not difficult to see the great impact of new media application on contemporary young people. Therefore, this paper specifically studies the impact of the rapid development of new media application on young people's life. The research method of this paper is to collect young people's use of new media and to conduct in-depth research on the specific impact of new media on young people. The main research tool is the questionnaire, which is put into the youth community mainly composed of college students to collect information about the time, frequency and preferences of young people using new media, and then sort out the data. After summarizing the data collected by the questionnaire, this paper discusses the convenience of new media in communication, work and entertainment while its negative impact on young people's lifestyle, social, ability and thought.
\end{abstract}

Keywords: New media, Mobile app, Internet user, Youth.

\section{INTRODUCTION}

On the night of July 13, 2021, the server of Bilibili was suspected to have suddenly crashed, causing the website, applications and small programs to be unable to be used normally. Although it was gradually restored to normal after a few hours, and the person in charge also issued a statement that it was caused by a power failure in the building. During this period, a large number of users of the website switched to other platforms. As a result, the servers of the other two platforms also crashed due to too much pressure and the page views of the topic on the topic platform about this event exceeded 6,000 in an hour. As China's largest bullet-screen video network, the collapse of bilibili site within hours caused such a big impact, joint multiple new media platform, reflect new media has a huge utilization rate, especially in young groups. Besides, it also has a profound impact to the audience. Understanding the impact of new media to young people's life and learning how to properly use the advantages of new media while avoid the negative effects of new media is of enormous significance for the better development of contemporary youth. This paper mainly takes youth as the research object to investigate the use of new media by contemporary youth, so as to understand the impact of new media on most youth groups. Analyze the current situation and influencing factors of young people's use of new media, so as to provide reference basis for guiding young to use new media correctly. To help youth avoid the adverse effects of new media and grow better.

\section{SURVEY ON YOUNG PEOPLE'S USE OF NEW MEDIA}

\subsection{Data Collection}

In order to study the impact of new media on young people's life, it is necessary to investigate how young people use new media and the specific situation of using new media. Therefore, the survey selected the youth community mainly composed of college students and collected data through questionnaire survey (A total of 180 valid questionnaires were issued, including 78 boys and 102 girls). In the data collected, only $1.11 \%$ of the people did not have too much contact with new media. 


\subsection{Data Description}

In the survey data, $56.11 \%$ of the people use new media applications every day, about a quarter of them use them three to four days a week, and only $5 \%$ of them use them two or less days a week. ("Figure 1") Most users (58.33\%) spent 1-3 hours a day, $13.33 \%$ spent less than 1 hour. $22.78 \%$ and $5.56 \%$ spent $3-5$ hours and more than 5 hours a day respectively ("Figure 2"). For the user preference, the most popular content types of young people are film and television, variety show and food, with $77.22 \%$ and $70 \%$ of the audience loving these two types of content respectively ("Figure 3").

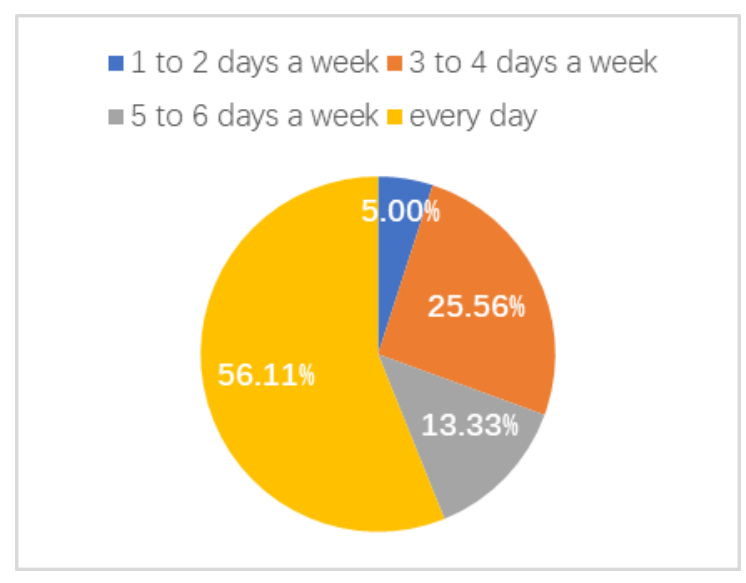

Figure 1 Situation of weekly usage.

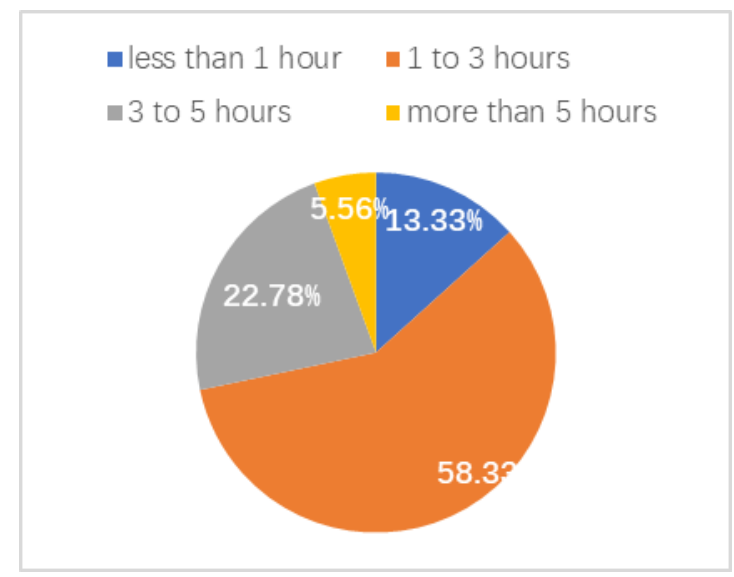

Figure 2 Situation of daily usage.

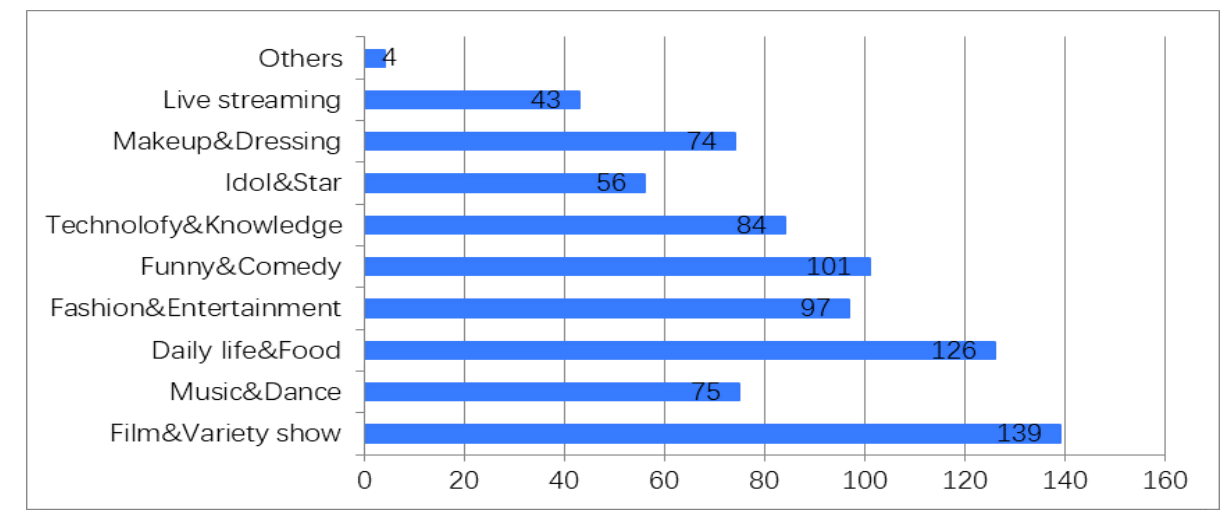

Figure 3 Situation of user preference. 
Besides, $87.22 \%$ of people use new media applications to relax and relieve pressure. $61.67 \%$ people want to acquire new knowledge through new media applications, $53.33 \%$ people choose to use new media to pass the time, while $52.22 \%$ and $51.11 \%$ people use new media applications to obtain food tutorials, travel strategies and other methods and obtain interesting ideas, respectively ("Figure 4"). In all data, $77.22 \%$ of the people will use new media applications at the end of their study or work, and $48.33 \%$ choose to use them when commuting and dining. In particular, the proportion of people who choose to use it before going to bed is as high as $61.11 \%$ ("Figure 5")

This paper mainly investigates the negative impact of new media. In all the survey data, only
$16.67 \%$ of young people think that the use of new media has no obvious impact on their lives. Two thirds of the people think that using new media will take up some time of study and work, and $59.44 \%$ think that using new media causes problems in life such as staying up late. ("Figure 6")

In addition, in the questionnaire, the situation of young people choosing new media application as their work was investigated. About $46.47 \%$ of young people have uploaded some content or live broadcast on new media applications. ("Figure 7") Among them, $54.1 \%$ were due to their interests, $19.67 \%$ chose to upload in order to earn money as a job, and $26.23 \%$ wanted to get fans' attention. In other words, one in five young people wants to make new media their job. ("Figure 8")

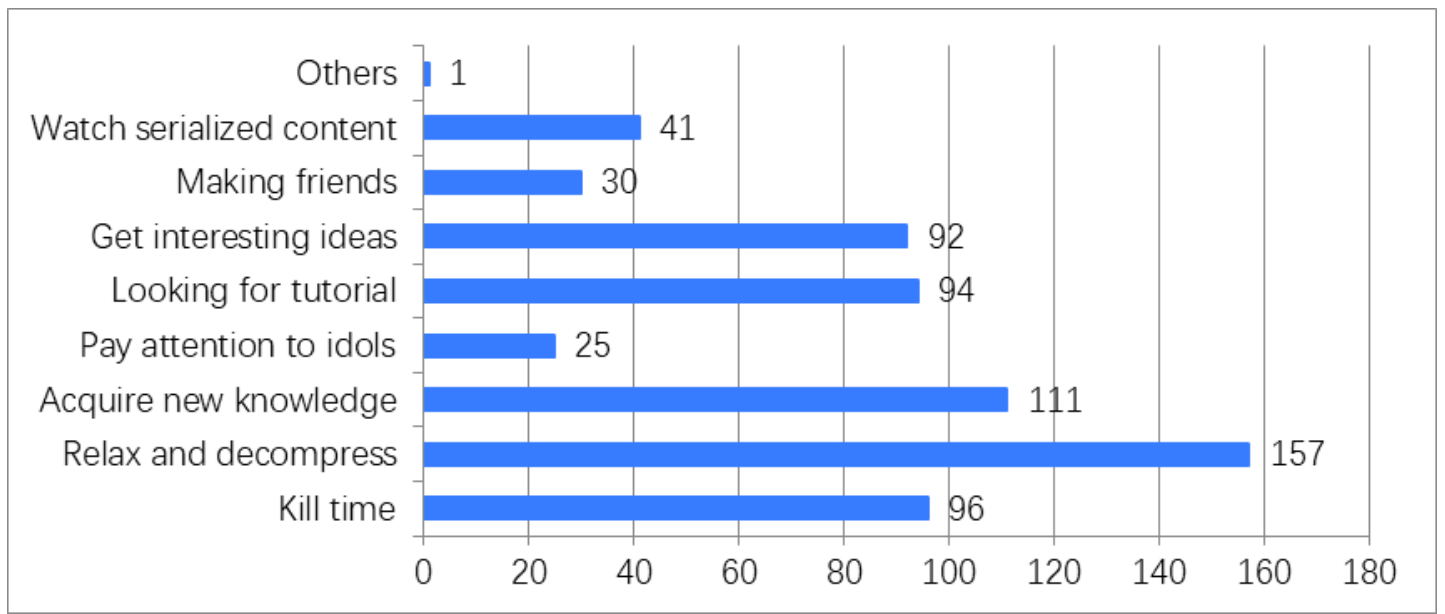

Figure 4 Situation of motivation.

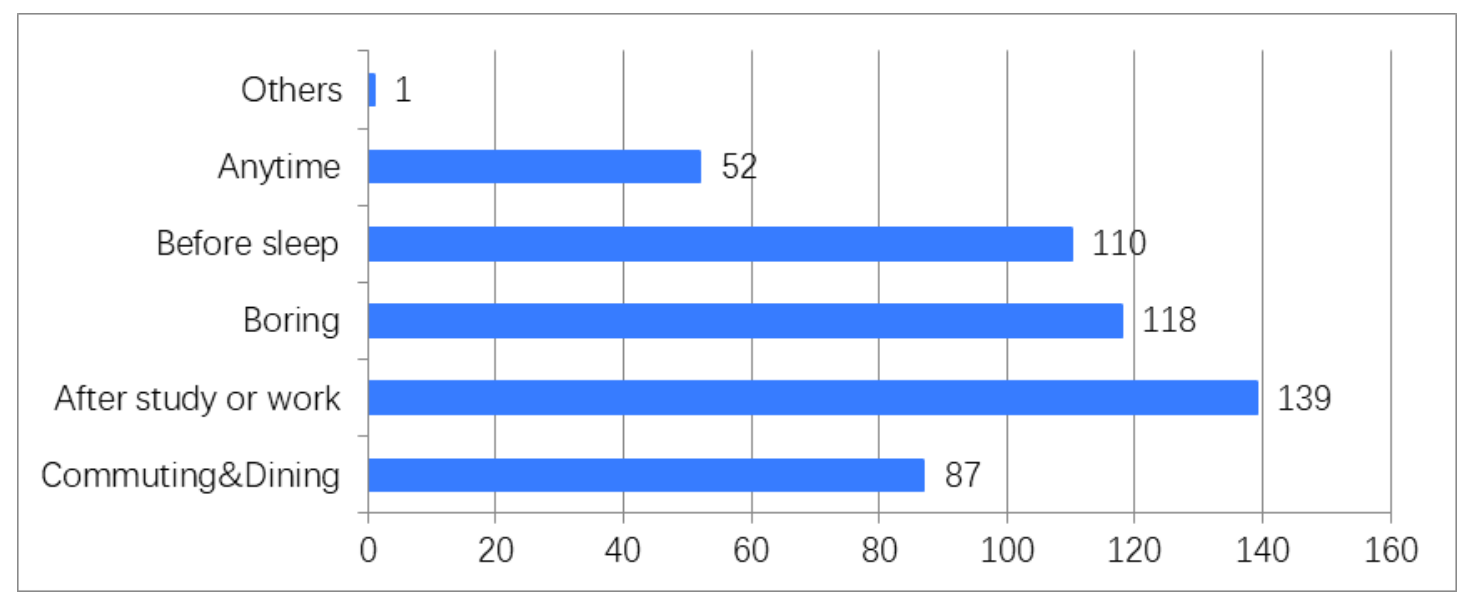

Figure 5 Situation of using time. 


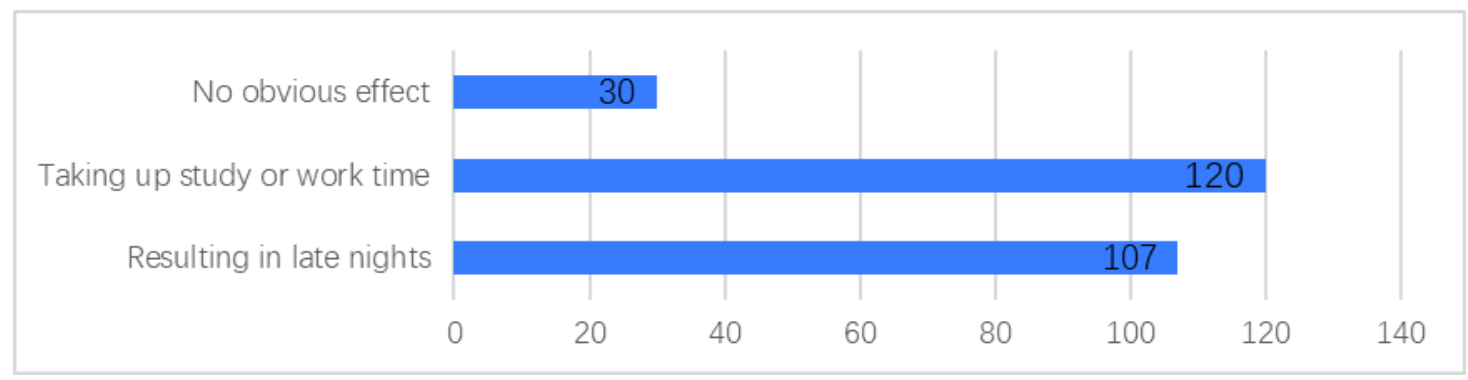

Figure 6 Situation of influence.

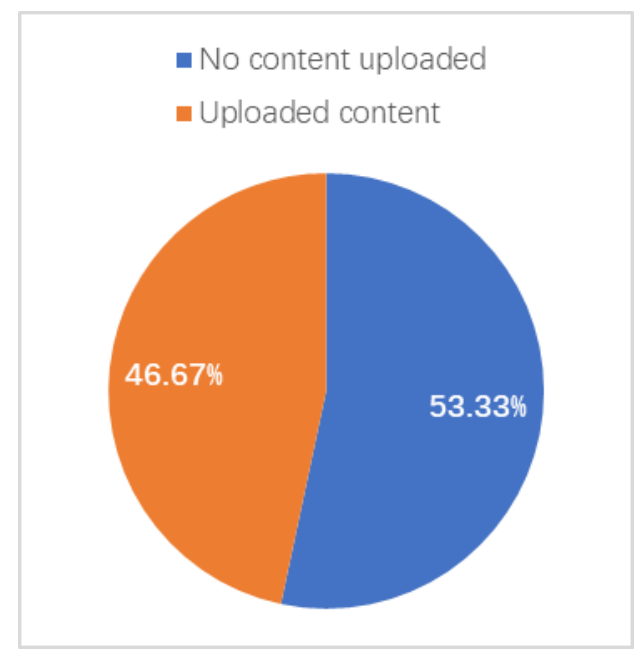

Figure 7 Situation of content-uploading.

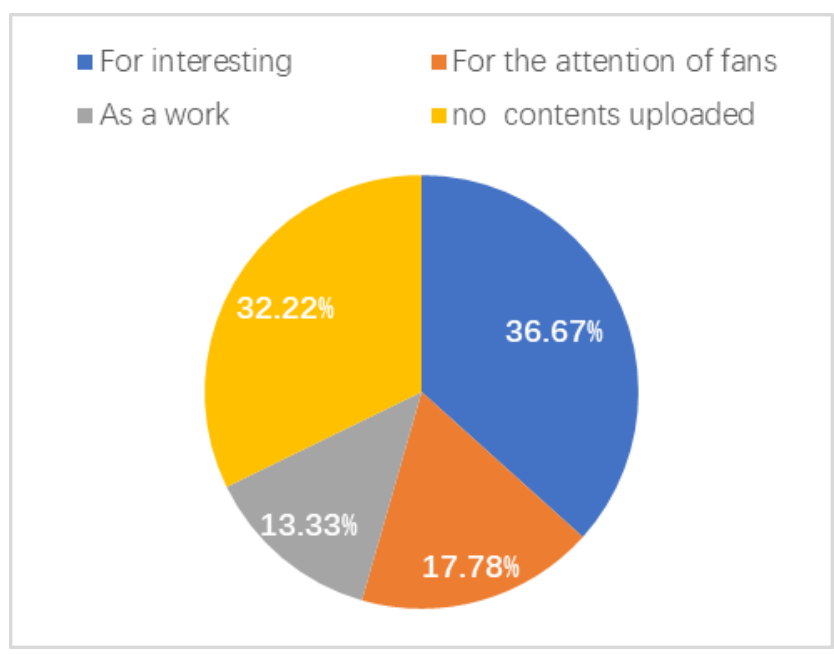

Figure 8 Situation of motivation of uploading.

\section{RESULT AND ANALYSIS}

According to the above analysis, the connection between new media application and young people's life is more and more close. More than half of young people use it every day, and most of them use it for about three hours. Combined with their preferences and motivations, it can be concluded that most young people use new media applications as a way to relieve pressure and cultivate interests. It is worth noting that the proportion of people who choose to use new media applications before going to bed is very high, which also corresponds to the phenomenon that nearly three fifths of people stay 
up late. Finally, it can be seen that for most young people, the negative impact of the application of new media mainly lies in its dispersion of normal life time, such as work, study, and even sleep.

\section{ANALYSIS OF THE INFLUENCE OF NEW MEDIA}

\subsection{Positive Influence}

\subsubsection{Way of Communication}

The rapid development of social media applications has greatly changed the way billions of people contact each other on the Internet. Various social media platforms have created a new mode of online dating, which enables contemporary youth to connect with people all over the world on the Internet[1]. At the same time, the increase of contact also broadens the access to information, people can get more comprehensive and reliable information more quickly and conveniently. Using these advantages properly could improve youth's professional level and cultivate their hobbies.

\subsubsection{Way of Working}

The development of live media has brought new ways of working. Since 2015, the live broadcasting industry has risen and developed rapidly. In 2017, the live broadcasting e-commerce platform with goods began to rise. In 2019, the live broadcasting e-commerce has become the mainstream of ecommerce development. According to statistics, about $70.41 \%$ of the people who pay attention to live broadcasting with goods are young people aged 18-30, becoming the largest audience of live broadcasting platform[2], which also helps more and more young people tend to combine their work with new media. Not only live with goods, each platform has more and more full-time bloggers. It's a good way to combine work with hobbies.

\subsubsection{Way of Entertainment}

many new forms of entertainment also emerge because of the development of new media. Video websites that reprint variety shows, movies and TV plays were popular about ten years ago and are still popular with many young people today. However, although the preference of video website is high, the choice rate of short video platform is little different from that of video website. Topic website, blog, lifestyle platform, shopping website and other new models are more and more popular among young people. These new media methods not only make the lifestyle of contemporary youth in all aspects more high-quality and convenient, but also enrich their entertainment methods

\subsection{Negative Influence}

\subsubsection{Influence on Lifestyle}

Nowadays, almost all young people use smart phones. It is obvious that the essence of young people's dependence on smart phones is their dependence on new media applications on their phones. In public transportation, it is often found that almost everyone uses new media applications in the whole process of commuting. This also gives rise to a new vocabulary - bow head clan.[3]

According to the survey, more than half of the youth associations choose to use new media applications before going to bed which greatly aggravates the problem of staying up late. This will affect not only their physical health, but also the mental state of the next day. Coupled with the lack of self-control of young people, it is easy to be occupied by these new media applications in their study and learning time. In the long run, it is easy to create a vicious circle

\subsubsection{Influence on Social}

The development of new media will weaken young people's interpersonal skills to a certain extent. Online social media generally convey information and mood through words and emoticons, which also makes users unable to directly feel each other's expressions and words transmission of emotion inefficient. Young people's interpersonal communication is limited to the mobile phone screen which causes the frequency of taking the initiative to talk with people around them is reduced.

With the rapid development of new media game platform, young people may be addicted to violent crime games for a long time. In addition, the legal and moral supervision system in the network world is lack of mature measures. It will make the young people gradually form the awareness and behavior of crimes endangering social security, and lead to the occurrence of deviant behavior.

\subsubsection{Influence on Ability}

The development of new media not only facilitates the life of young people, but also makes 
them lose some basic abilities. For example, the rise of smart phones has popularized the use of electronic keyboards. This just makes the young people's writing ability slowly become poor[4].Especially in college students, paperless learning has gradually replaced the traditional way of learning, so that college students often use handwriting in the final exam and always feel uncomfortable when they write.

Besides, the use of electronic navigation reduces the situation that drivers go wrong. On the contrary, it also makes many young drivers rely heavily on navigation, so that they don't know the road even they have passed without navigation.

\subsubsection{Influence on Thought}

The information transmitted by new media applications is timely and diverse. Young people with insufficient knowledge will frequently use new media to obtain information. But at the same time, this trend is slowly engulfing young people's innovative thinking and autonomous learning. At the same time, the information exchange of new media is anonymous, which will breed criminals to spread fraud information, create rumors and information smoke.[5] This kind of Internet public opinion can easily make young people deliberately believe, make wrong judgments and lose themselves.

In addition, young people are vulnerable to the influence of Internet Celebrities, stars and peers, blindly following the trend. With tiktok and other social software rising rapidly, all kinds of information are transmitted among young people. At the same time, the wearing articles and other information of stars and net celebrities are also focused by young people. For example, when some anchors recommend a product in the live broadcast room and mention that the product is the same model with a certain star or co branded with a certain brand, it will stimulate young people's consumption desire to make them want to buy to show their love for a certain star or loyalty to a certain brand. When peers buy famous brands, some young people will blindly compare to meet their vanity[6].

\section{CONCLUSION}

As the main user group of new media applications, the development of new media has a profound impact on young people. On the one hand, it expands youth's access to information, provides their a new way of working, such as live broadcast, and enriches youth's life and entertainment. On the other hand, it also has a negative impact on young people's lifestyle, social, ability and thought. With the popularization of new media applications and the continuous improvement of network platform, contemporary youth should conform to the trend of the times, make good use of the advantages of the Internet and let it become a tool to improve themselves. But at the same time, enhancing self-discipline and using new media rationally to avoid many negative effects of life brought by new media is vital too. For the overall situation of this paper, there are still some deficiencies, such as there are not many survey samples, the conclusions are more biased towards theory and so on. For future research, the survey population needs to be expanded to obtain more sufficient data to ensure the accuracy. In addition, the next research direction will focus on practical points such as how to avoid the impact of new media on teenagers and how to make rational use of the advantages of new media.

\section{AUTHORS' CONTRIBUTIONS}

This paper is independently completed by Fei Wang.

\section{ACKNOWLEDGMENTS}

What I need to thank most is my English teacher. As my first English paper, I was very vague in the format of the paper, including the structural requirements. The teacher is very patient to help me sort out the relevant requirements, let me have a clear framework for the whole paper. And the teacher also gave me some advice on grammar and ideas. In addition, I would also like to thank the students of related majors. At the beginning, the topic selection was rather tangled. This student helped me analyze the pros and cons of each topic, so that I determined the final topic

\section{REFERENCES}

[1] David Camacho; M a Victoria Luzón; Erik Cambria. New trends and applications in social media analytics[J].Future Generation Computer Systems, 2021,114:318-321.

[2] Zheng Kaixin, Wu Han, Hu Fuhui, Li Yang, $\mathrm{Xu}$ Xun. Statistical analysis and development strategy research of online celebrities' live 
streaming with goods in the era of big data $[\mathrm{J}]$. Marketing. 2021(31): 25-27 (in Chinese)

[3] Yang Meixin, Sun Lingling. Analysis on the Negative Influence of Mobile Phone New Media on College Students' Ideological Behavior [J]. Media Forum. 2021(10):171172(in Chinese)

[4] Lu Zhuoyuan; Zhang Xiaohu. The Influence of Campus New Media Platform on the Writing Ability of Students With New Engineering Background[J]. Journal of Physics: Conference Series, 2021,1915(4).

[5] Wang Ling, Xin Hui. Analysis of Factors Influencing Short Video on College Students' Consumption in the Era of New Media [J]. China Market. 2021(16):196-198(in Chinese)

[6] Meng Keira Shuyang; Leung Louis. Factors influencing Tik Tok engagement behaviors in China: An examination of gratifications sought, narcissism, and the Big Five personality traits[J]. Telecommunications Policy, 2021,45(7). 